\title{
DESIGN PARA EXPERIÊNCIA E COMPUTACÃO FÍSICA: UMA PROPOSTA DE ANÁLISE
}

\section{DESIGN FOR EXPERIENCE AND PHYSICAL COMPUTING: AN ANALYSIS PROPOSAL}

Ricardo Toller Correia ${ }^{1}$ Maurício Elias Dick² 


\section{Resumo}

Incorporar elementos tecnológicos a produtos permite ao designer dar novo significado ao uso daquele determinado artefato, proporcionando a exploração de novas experiências. Nesse contexto, a computação física, caracterizada pela capacidade de tornar computadores sensíveis aos humanos e ao ambiente pode servir como suporte à inovação. Para compreender como aliar essa tecnologia ao design para experiência, este estudo busca identificar a relação entre a computação física e o Design focado na experiência, propondo uma análise qualitativa para auxiliar no entendimento da experiência e dos aspectos tecnológicos de projetos desta natureza. A construção da análise se deu com base em aspectos do design para experiência estudados por autores que abordam suas classificações, estágios e níveis. Concluiu-se que o caráter sensorial da computação física abre espaço para explorações das camadas estéticas da experiência. Além disso, considerou-se a proposta de análise eficaz no auxílio ao designer durante projeto de design para a experiência ligado à computação física.

Palavras-Chave: design; experiência; computação física; análise.

\section{Abstract}

Embodying technology to projects allows designers to give new meanings to a product's use, providing the opportunity of exploring new experiences. In this context, physical computing, characterized by its ability to make computers sensitive humans and to the environment can be used as a innovation support. To comprehend how to integrate this technology to Design projects for experience, this research aims to identify the relation between physical computing and Design for experience, introducing a qualitative analysis to help understanding the experience and the technological aspects of projects of this nature. The construction of the analysis is based on Design for experience aspects studied by authors, including classifications, layers and stages of an experience. It was concluded that the sensory aspect of physical computing allows explorations of the aesthetic layers of experience. Furthermore, the proposed analysis was considered effective to assist the designer during the design for experience project linked to physical computing.

Keywords: design; experience; physical computing; analysis.

ISSN: $1808-3129$
${ }^{1}$ Ricardo Toller Correia

Graduado em Desenho Industrial - Programação Visual pela Universidade Federal de Santa Maria (UFSM) ricardotcorreia@gmail.com
${ }^{1}$ Maurício Elias Dick

Universidade Federal de Santa Maria

mauricioedick@gmail.com 


\section{INTRODUÇÃO}

Ao final do século $X X$, surge o conceito de Economia da Experiência, o qual indica que produtos e serviços não são mais suficientes para o público em geral. Atualmente, é possível identificá-la a partir do inquestionável desejo das pessoas por experiências, com cada vez mais empresas e negócios buscando formas de responder a estes anseios. Mas, para perceber-se o potencial dos benefícios que proporcionar experiências às pessoas pode trazer, deve-se deliberadamente projetá-las para serem engajadoras (PINE II; GILMORE, 1998).

Juntamente, as novas tecnologias estão constantemente mudando os hábitos e preferências das pessoas, levando-as diariamente a territórios não explorados. A telefonia móvel e as redes sociais integraram tecnologia e estilo de vida de uma maneira que dificilmente a sociedade teria previsto na década precedente, da mesma forma que ocorrera com as demais tecnologias em diferentes épocas. De ir ao banco a cozinhar, de cuidar da saúde a cuidar das finanças, as pessoas tem realizado suas atividades de maneiras diferentes do que estavam acostumadas (CHIU, 2014). Fruto dessa evolução, tem-se a computação física, onde esta caracteriza-se como o modo de interação entre humanos e computadores que considera as formas em que as pessoas se expressam fisicamente, tendo como ponto de partida o corpo humano e suas capacidades (ITP PHYSICAL COMPUTING, [2014?]).

Nesse sentido, $O$ ato de incorporar tecnologia a produtos potencializa a capacidade de redefinição da função de objetos já existentes e desta forma permite que novas experiências sejam desenhadas para formas já conhecidas. Tal apropriação aproxima-se da postura que visa valorizar a importância da não-funcionalidade como uma forma de expressão, por exemplo, explorando humor e ironia nos objetos, muitas vezes subvertendo os seus usos como propõe o design para a experiência atualmente, como define Nardelli (2007).

O design para a experiência e as possibilidades no campo da computação física estão, portanto, relacionados pela expressividade que podem conferir a um produto.

Nesse contexto, insere-se a importância do projetista compreender como integrar a computação física a projetos de Design para experiência, de modo a utilizar a tecnologia como aliada na geração de experiências inovadoras. Para tal, este estudo busca identificar a relação entre a computação física e o Design focado na experiência, propondo uma análise qualitativa para auxiliar na compreensão da experiência e dos aspectos tecnológicos de projetos desta natureza. 


\section{DESIGN PARA EXPERIÊNCIA}

No livro "A Fantástica Fábrica de Chocolate", Charlie é um menino de família pobre que encontra um cobiçado cupom dourado para um dia de aventuras inesquecíveis em uma fábrica de chocolates. Desta maneira, Marc Hassenzahl (2014) exemplifica o poder das experiências na vida das pessoas: Charlie, o menino pobre, renuncia dos benefícios que a venda deste cupom poderiam lhe trazer para embarcar em uma experiência extraordinária. De fato, estudos comprovam que a aquisição de experiências (como jantares, eventos, concertos) trazem mais felicidade às pessoas que aquisições materiais (como roupas, jóias, carros) do mesmo valor (BOVEN; GILOVICH, 2003; CARTER; GILOVICH 2010 apud HASSENZAHL, 2014).

Manzini e Meroni (2005) ressaltam que projetar a experiência significa projetar uma situação estabelecendo seus limites e fomentando sua realização. Logo, projeta-se uma série de condições e trabalha-se com uma probabilidade de que os eventos ocorram de maneira planejada, mas não se projeta a experiência em si. A experiência é guiada pelo próprio usuário, com sua própria bagagem cultural e percepção, gerando uma experiência individual.

O design para experiência tem por objetivo influenciar as emoções do usuário por meio da manipulação de elementos tangíveis, controlando qualidades sensoriais, formais e comportamentais a fim de estimular determinadas emoções. Ressalta-se ainda a importância de enxergar os objetos não só como instrumentos solucionadores de problemas do dia a dia, mas sobretudo de pensar as relações entre objetos e indivíduos de maneira mais ampla para além da questão de uso, cuidando de outras instâncias e formas de apropriação possíveis (MILLER, 2002 apud THIEME, 2012).

Desta forma, Shedroff (2009) conclui que, caso os elementos que tornam certas experiências superiores sejam identificados e reproduzidos, então estas experiências podem ser projetadas, o que as tornam potenciais objetos de Design.

O autor, então, propõe três estágios principais para a experiência:

A atração é necessária para iniciar a experiência. Pode ser cognitiva, visual, auditiva ou outro sinal para os sentidos. A atração pode ser intencional ou parte da experiência. $\mathrm{O}$ engajamento é a experiência em si. Para existir interesse em continuar a experiência é necessário que esta seja suficientemente diferente do ambiente à sua volta - a fim de reter a atenção do usuário - e que seja cognitivamente importante. A conclusão pode vir de várias formas, mas ela sempre deve prover algum tipo de resolução, seja por significado (um desfecho pelo próprio contexto) ou por uma atividade agradável e satisfatória. Ainda é possível uma extensão da experiência; algo que possa meramente prolongar a experiência, revivê-la, ou formar uma ponte para outras experiências (SHEDROFF, 2009, grifo nosso).

Além dos estágios definidos por Shedroff (2009), Buccini (2006) sugere seis categorias de experiência:

Experiências relacionadas aos sentidos: são consideradas as mais básicas e diretas, pois estão diretamente ligadas aos órgãos sensoriais.

Experiências relacionadas aos sentimentos: configuram as reações emocionais provenientes do uso de um produto, exigindo um nível cognitivo mais avançado.

Experiências sociais: são aquelas que ocorrem entre indivíduos mas são inter- 
mediadas por um produto.

Experiências cognitivas: são relacionadas ao pensamento e à interpretação de códigos pelo usuário.

Experiências de uso: abordam aspectos referentes à usabilidade e funcionalidade dos produtos.

Experiências de motivação: acontecem quando um produto é responsável por um comportamento específico do usuário.

Ainda, de acordo com Desmet e Hekkert (2007) é possível distinguir três componentes da experiência de um produto: o componente Estético, de Significado/Valor e Emocional (Figura 1).

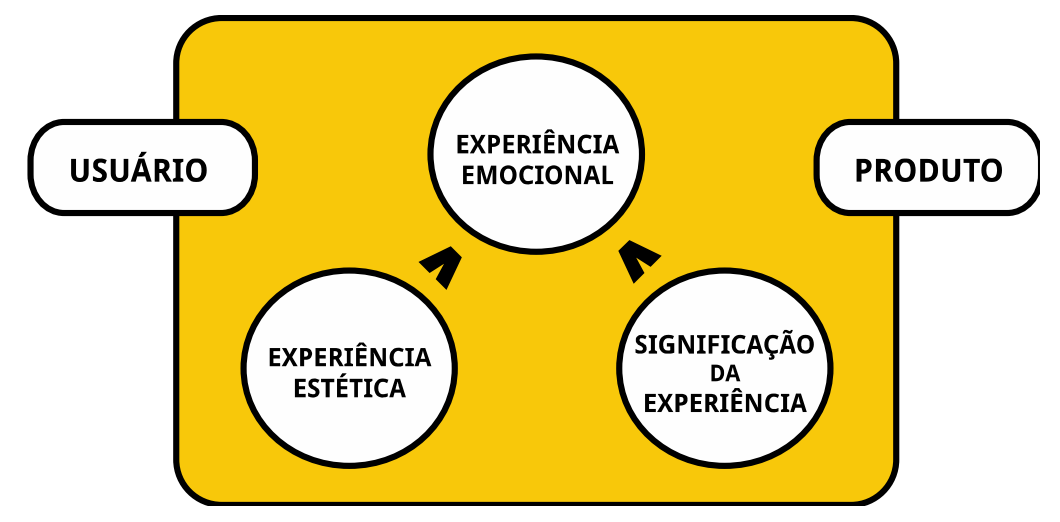

Figura 1: As camadas da experiência de produtos. Fonte: Adaptado de Desmet e Hekkert (2007).

A experiência estética está diretamente relacionada à experiência sensorial, definida por Desmet e Hekkert (2007) como a capacidade de satisfazer um ou mais sentidos sensoriais. Conforme Löbach (2001), a função estética dos produtos é a relação entre um produto e os usuários em níveis sensoriais, ou seja, "é um aspecto psicológico da percepção sensorial durante o seu uso".

De acordo com Lindstrom (2007), "a exploração individual dos sentidos oferece apenas uma faceta da realidade, tornando quase impossível criar o quadro completo". Isto porque todos os sentidos estão, de certa forma, interligados: ouve-se com olhos, saboreia-se com o nariz, vê-se com as mãos.

A Cochlear, responsável por implantes de dispositivos eletrônicos que visam proporcionar aos seus usuários sensação auditiva, produziu um catálogo de fotografias que capturam o mundo dos sons, apropriando-se dessa forte relação de sentidos. Dentre as imagens, uma baleia batendo sua cauda no mar (Figura 2), registrada por Sebastião Salgado, evoca o som do mar e o agito que seu movimento causa. 




Figura 2: Imagem que evoca som. Fonte: Sebastião Salgado (2004).

Löbach (2001) aborda a questão como multi-sensorial: muito embora nem todos os sentidos sensoriais sejam explorados durante a criação de um produto, "são ativados todos os sentidos do homem de forma global, sendo raramente possível uma percepção unidimensional".

Para Okamoto (2002 apud BRAIDA; NOJIMA, 2011) confirma-se a necessidade de aprimoramento sensorial, ou seja, é preciso sentir as texturas da vida novamente, valorizando-as como condição para recuperar a beleza dos sentidos.

A camada de significação de Desmet e Hekkert (2007) é a camada da experiência em que atribui-se algum significado pessoal ao produto. Ela se dá através de processos cognitivos, ou seja, usa-se o poder de interpretação e a memória para buscar em experiências passadas e realizar associações, para então poder-se reconhecer metáforas, atribuir personalidade e avaliar o valor simbólico e pessoal de produtos (DESMET; HEKKERT, 2007). Norman (2008) afirma, entretanto, que só avalia-se cognitivamente uma situação depois de avaliar-se emocionalmente, pois a sobrevivência é mais importante que a compreensão.

A camada de significação aproxima-se do conceito de Função Simbólica de Löbach (2001): "quando a espiritualidade do homem é estimulada pela percepção deste objeto, ao estabelecer ligações com suas experiências e sensações anteriores".

A emoção é desenvolvida a partir de processos de avaliação de um evento ou situação, ou seja, são os significados pessoais e particulares atribuídos a um produto que determinam as emoções, e não o produto em si. Este processo de avaliação da relação de significação de um estímulo é chamado de appraisal. Por exemplo, uma pessoa estressada pode se irritar com o alarme de seu telefone celular pois avalia isto como indesejável no momento, entretanto, outra pessoa pode avaliar a mesma situação como desejável e ter reações positivas ao alarme (DESMET; HEKKERT, 2007).

De acordo com Forlizzi e Battarbee (2004), do ponto de vista do Design, a emoção conecta o vão entre pessoas e produtos no mundo, servindo como uma ferramenta para entender e comunicar as experiências. Desta forma, "a emoção afeta a maneira como nós planejamos interagir com os produtos, como nós realmente interagimos com eles e as conclusões que tiramos disso" (FORLIZZI; BATTARBEE, 2004, p.264). 


\begin{abstract}
O vínculo afetivo a determinados produtos não está relacionado necessariamente as suas funções práticas e utilitárias, pois fatores mais subjetivos exercem maior influência. Os significados simbólicos apresentam-se como os principais determinantes do vínculo afetivo. Quando uma pessoa especial toca fisicamente um produto ou o produto foi obtido em um contexto especial e o tornou exclusivo para seu proprietário, esse produto pode ser considerado insubstituível. A percepção de que um produto é considerado indispensável, por exemplo, muitas vezes é assim não por razões práticas, mas por razões emocionais (SCHIFFERSTEIN; ZWARTKRUIS-PELGRIM, 2008 apud CARDOSO et al. 2010).
\end{abstract}

Desse modo, entende-se que as diferentes camadas da experiência estão interligadas, onde a experiência estética e significação culminam na atribuição de valores sentimentais a um produto. Já, a partir da experiência estética envolve-se prazer e desprazer, procurando produtos que se encaixem nestas expectativas. Somado a isso, o significado atribuído permite que os processos de interpretação criem condições para os produtos e situações serem avaliados, gerando sentimentos em relação a estes.

\title{
COMPUTAÇÃO FÍSICA
}

O'Sullivan e Igoe (2004) afirmam que é preciso pensar em computadores que sintam mais os corpos das pessoas, estejam disponíveis em mais situações, e que não só transmitam informação, mas também expressão física. Segundo os autores, a computação física surge, então, como um meio para criar a conversação entre o mundo físico e o mundo virtual dos computadores.

Ao se pedir para alguém descrever um computador, provavelmente se ouviria algo próximo a: tela, teclado e mouse. É esta imagem que está impregnada no imaginário popular quando refere-se a computadores. Entretanto, para que possa-se explorar completamente as possibilidades da computação, deve-se romper com este estereótipo. É necessário pensar sobre computação em vez de computadores. Desta maneira, uma abordagem mais abrangente sobre computadores vê as pessoas como fonte de interesse, e cabe a eles capturar e transmitir as expressões destas pessoas.

De acordo com Banzi (2011), a computação física utiliza elementos eletrônicos para prototipagem de novos projetos de design ou arte, envolvendo a criação de objetos interativos que podem comunicar-se com os humanos, ambiente ou entre os próprios computadores. "Em computação física, considera-se o corpo humano como fator evidente, e busca-se projetar dentro de seus limites de expressão" (IGOE, 2014).

Segundo O'Sullivan e Igoe (2004), a primeira etapa em projetos de computação física é descrever o que se almeja que aconteça. Descrever claramente o que acontecerá, em linguagem verbal, é primordial para que se possam construir circuitos e escrever uma programação para que isto, de fato, aconteça. Os autores sugerem que descreva-se o ambiente em que o projeto está inserido a partir do ponto de vista do usuário que irá experienciá-lo.

Depois da descrição e reflexão sobre o conceito em linguagem verbal - sem de- 
ter-se a questões tecnológicas - deve-se então desdobrar esta ideia nos três estágios principais da computação física: o input, o processamento e o output.

É importante questionar-se, por exemplo, se o input virá do usuário ou do ambiente, ou talvez da ação do usuário sobre o ambiente. Que tipo de ação o output desenvolverá? A maioria dos projetos de computação física pode ser dividida nestes três estágios principais: ouvir, pensar e falar. Estes estágios correspondem ao input, processamento e output, respectivamente. Compreender claramente os papéis destes estágios permite que se foque nos detalhes do projeto (O'SULLIVAN; IGOE, 2004).

\section{Componentes da computação física}

Além dos estágios principais, Seymour (2008) classifica os sete componentes técnicos usados na computação física: microprocessadores, interface, inputs, outputs, programação, energia e materiais.

O microprocessador (Figura 3) é um computador de pequenas proporções que é capaz de executar e armazenar um programa. Seu papel é coletar e computar dados derivados oriundos dos sensores de entrada, sendo responsável também por enviar as saídas da interpretação dos dados coletados (SEYMOUR, 2008)

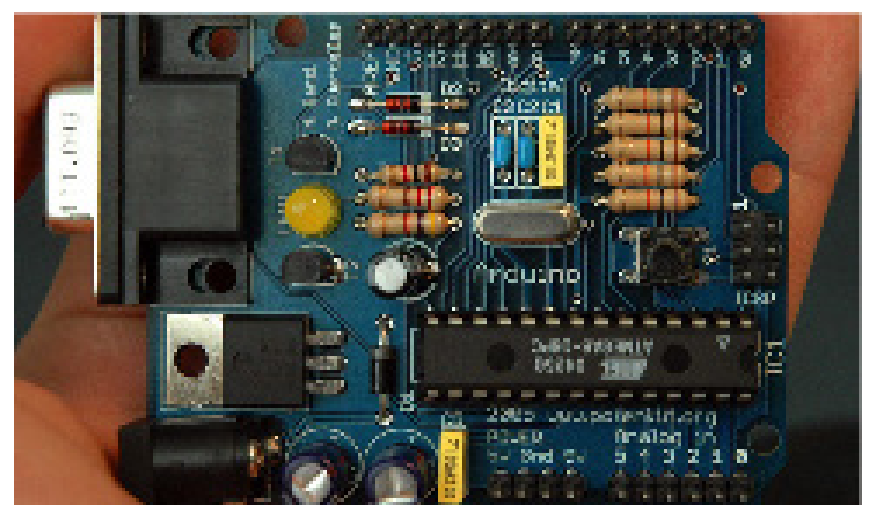

Figura 3: Microprocessador Arduino. Fonte: Wikipedia (2014).

A interface se refere aos cabos, conexões, antenas, ou seja, é o meio pelo qual os periféricos conectam-se com o microprocessador e entre si. Existem diversos meios propícios para este fim: tecidos condutivos, cabos, linhas condutivas, Bluetooth, e até peças de metal comuns do vestuário como zíperes e botões.

O input, por sua vez é uma informação, um dado, recebido pelo sistema para ser processado. É a forma de comunicação de um computador com o mundo externo, como uma pessoa, por exemplo. Muitos projetos de computação física usam sensores (Figura 4) para capturar dados como forma de iniciar uma interação. Estes dados podem ser provenientes do ambiente (luz, por exemplo) ou do usuário (movimento do corpo, por exemplo). 


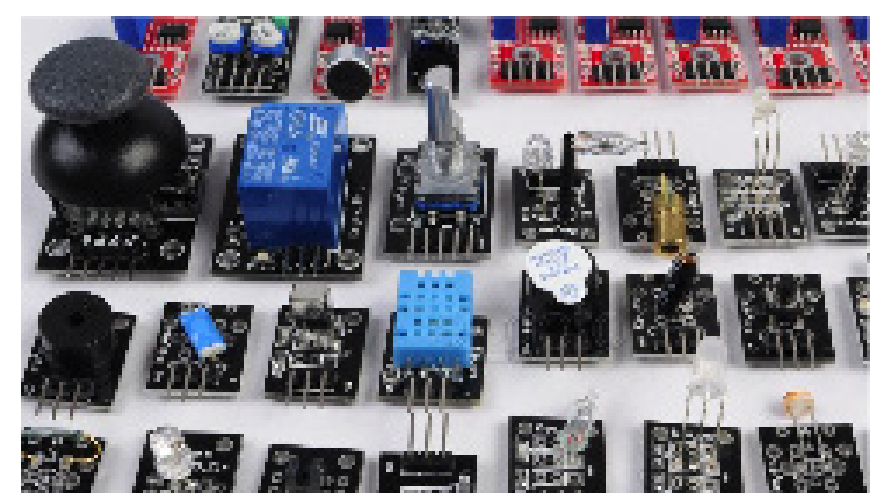

Figura 4: Variedade de sensores. Fonte: Wikipedia (2014).

Os sensores são componentes eletrônicos que medem aspectos do mundo físico e convertem esta medida em valores elétricos variáveis, como voltagem e resistência. Eles podem detectar luz, movimento, temperatura e toque. Sensores são empolgantes, pois tornam o mundo físico perceptível por computadores (HARTMAN, 2014).

Enquanto o input está ligado às possibilidades de sentir as ações do usuário sobre o produto ou aos aspectos do ambiente, o output é a resposta a estes estímulos, ou seja, a saída do sistema. Em geral, são usados Atuadores para desempenhar essa função. Os atuadores são as peças que vibram, piscam, emitem sons, esquentam, esfriam; ou seja, são responsáveis por estimular os sentidos do usuário ou público (SEYMOUR, 2008). Alguns exemplos de outputs (e atuadores) vínculados a determinados sentidos são: LEDs, telas, tintas térmicas e fibras óticas (visão); alto-falantes e alarmes (audição); motores, tecidos condutivos, vibradores, aquecedores (tato); e cápsulas de cheiro relacionadas ao olfato e ao paladar.

Uma vez que input e output compõem as partes físicas da computação física, a terceira parte requer que um computador leia o input, tome decisões baseadas nos valores que ele lê e que necessita-se a programação. Segundo O'Sullivan e Igoe (2004), a programação para microcontroladores usados em computação física costuma ser bastante breve e simples: ler sensores, ligar e desligar outputs e enviar mensagens pra outros computadores.

Além disso, o funcionamento dos dados capturados através de microprocessadores requer energia. Atualmente, a principal fonte de energia para peças que integram tecnologia a projetos que necessitem certa mobilidade são as baterias. Por fim, os diferentes materiais em conjunto com pesquisas atuais em nanotecnologia, biotecnologia, e tecnologias digitais permitem uma integração verdadeira da função e estética do sistema de computação física (SEYMOUR, 2008).

\section{Computação física para experiência}

Descreva o que se vê, ouve, e sente e o que pode-se fazer para interferir no ambiente. Descreva a experiência e seu desenvolvimento, o que muda quando uma pessoa executa diferentes ações e como sua atenção e suas ações são afetadas por estas mudanças. Descreva o porquê isto seria envolvente para a pessoa e como a sequência de eventos deve funcionar para mantê-la engajada (O'SULLIVAN; IGOE, 2004, p. xxii). 
O caráter interativo da computação física abre diversas possibilidades para explorar o viés emocional, de significado e, sobretudo, sensorial de projetos. Sua própria estrutura dividida em input, processamento e output sugere que ações do usuário ou ambiente causarão uma reação física, o que potencializa a participação do usuário no funcionamento do projeto e lhe concede uma sensação de influência sobre o produto.

A luminária "The Smoking Lamp" de Helen Evans e Heiko Hansen, por exemplo, usa sensores que detectam fumaça de nicotina. Se detectada, as luzes da lâmpada mudam para uma tonalidade magenta. A intenção é gerar um questionamento paradoxal acerca das opções de ação: o fato do produto gerar uma resposta à fumaça é extremamente convidativo e desperta o desejo, porém, por estar instalada em lugares fechados, o ato de fumar pode ser considerado uma transgressão. Cabe, portanto, ao usuário tomar a decisão. Ao promover a expressividade de produtos, ou seja, fazê-los falar, movimentar, vibrar, aquecer, responder à ações, a computação física abre caminho para exploração, criações e apropriações de produtos e formas de comunicação. É como se objetos ganhassem vida: podem detectar ações, pensar sobre elas e respondê-las. Com isso, é possível ressignificar simples experiências como fumar, regar plantas, abraçar, conversar.

Já o projeto Botanicalls (Figura 5) almeja estabelecer uma comunicação entre pessoas e plantas, criando novos meios para interação. Ao monitorar a umidade da terra que rodeia a planta, o circuito define se há ou não necessidade de regá-la. Caso positivo, haverá um output indicando esta necessidade: um tuíte, uma ligação, uma mensagem informando que o dono precisa regar seu vaso.

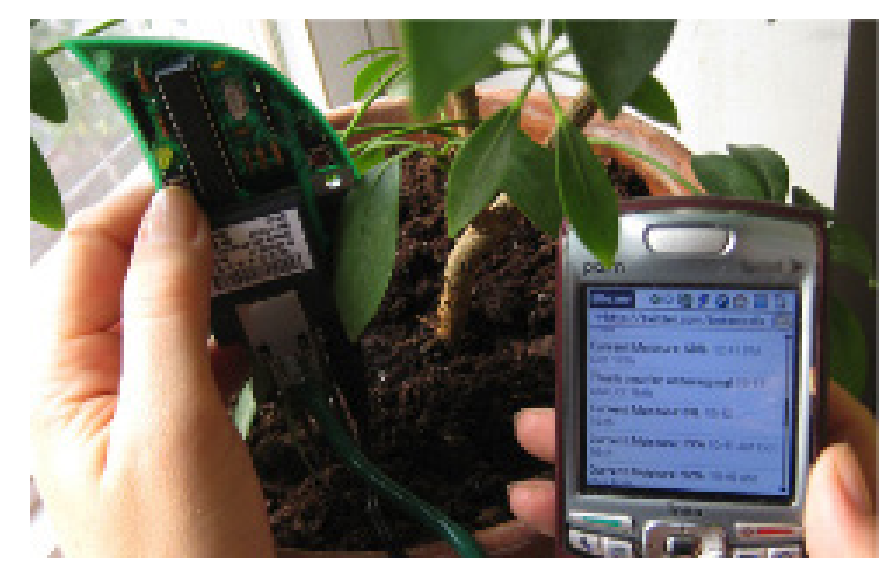

Figura 5: Botanicalls. Fonte: Botanicalls (2014).

Nessa experiência, embora não esteja diretamente envolvida no processo, à planta é atribuída a capacidade de telefonar ou interagir com o usuário. Ao conferir ações humanas à planta, esta interação inusitada entre um humano e um vegetal destaca-se como uma forte experiência social, abordada por Buccini (2006): aquelas que ocorrem entre indivíduos, mas são intermediadas por um produto. Desse modo, os caminhos e possibilidades abertos pela computação física são relevantes ao Design com foco na experiência. 


\section{PROCEDIMENTOS METODOLÓGICOS}

Com o intuito de auxiliar na compreensão da experiência e dos aspectos tecnológicos de projetos que aliam experiência e computação física, foram desenvolvidas análises qualitativas que contemplam as principais caraterísticas e componentes destas áreas. Assim, a experiência foi analisada conforme os estágios propostos por Shedroff (2009), as classificações de Buccini (2006) e os níveis de Desmet e Hekkert (2007). Já a computação física foi analisada conforme os estágios principais descritos por O'Sullivan e Igoe (2004): input, processamento e output, formando o Quadro 1. Desta forma, foi possível averiguar as relações sensoriais, atribuição de valores e emoções durante cada estágio da experiência de interação, constatando a expressividade promovida pelo uso da computação física nos projetos que foram objeto de análise.

\begin{tabular}{|c|c|c|}
\hline $\begin{array}{c}\text { CATEGORIAS DA } \\
\text { EXPERIÊNCIA } \\
\text { conforme Buccinui }\end{array}$ & $\begin{array}{c}\text { ESTÁGIOS DA } \\
\text { EXPERIÊNCIA }\end{array}$ & $\begin{array}{c}\text { NIVEIS DA EXPERIÊNCIA } \\
\text { baseados em Shedroff (2009) }\end{array}$ \\
\hline INPUTS & PROCESSAMENTO de Desmet e Hekkert & $(2007)$ \\
\hline
\end{tabular}

Quadro 1: Quadro desenvolvido para a análise da experiência em computação física. Fonte: autores.

\section{RESULTADOS E DISCUSSÕES}

\section{Análise I - Momentos de calor}

Desenvolvida pela agência canadense Cossette para marca Duracell, a campanha publicitária chamada "Momentos de calor" foi instalada no gélido inverno de Montreal, no Canadá. Buscando aproximar as pessoas que aguardavam ônibus em estações, os anúncios pediam que os usuários criassem uma corrente humana, dando as mãos, que uniria as duas extremidades da estação, onde haviam representações de mãos sinalizando onde se deveria encostar. Essa ação resultava no aquecimento momentâneo da estação. 


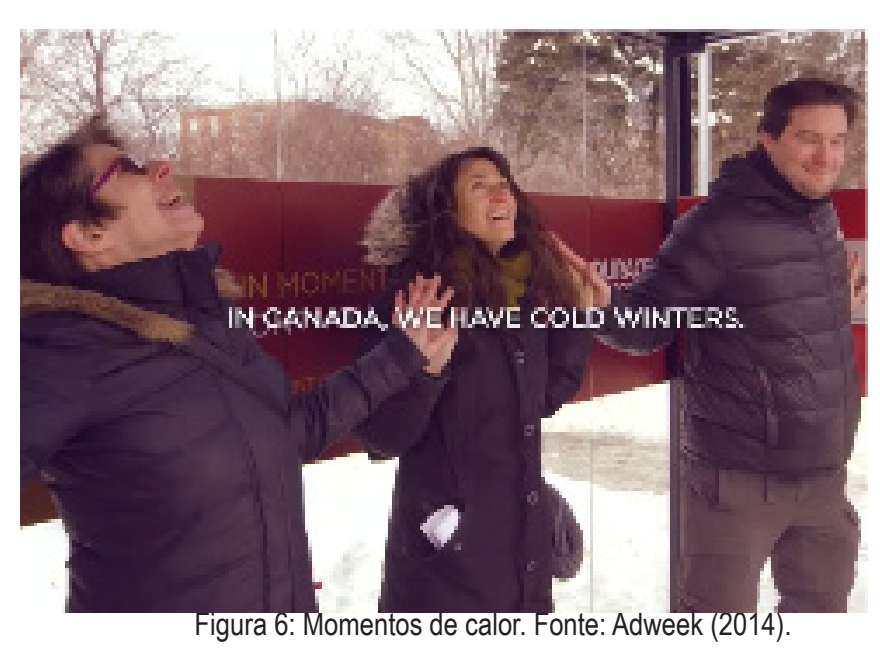

Em termos tecnológicos, é possível observar que pode haver mais de uma maneira de sistematizar este circuito. Pode-se observá-lo como um circuito simples, sem sensores: há um ponto em cada extremidade da estação de ônibus, ligados à um aquecedor na parte superior (output). Tem-se portanto, um circuito aberto onde falta uma conexão entre as extremidades da estação. O corpo humano é composto, em grande parte, por água e há água e minerais em nossa pele, ou seja, ele é um condutor, embora muito fraco. Assim, duas pessoas de mãos dadas encostando as extremidades da estação completam o circuito e acionam o output, que aquece o ambiente. A proposta de união entre pessoas, que se conhecem ou não, com um objetivo único em uma ação pode ser associado a diversas mensagens: aproximar pessoas, a união em prol de alguma causa, a união faz a força, etc. Assim, esta experiência aborda questões de proximidade e intimidade entre pessoas, que se veem forçadas a interagir para que o sistema se complete.

A atração, estágio inicial da experiência, é visual pois as indicações e explicações contidas nas extremidades da parada de ônibus são as únicas instruções aparentes para convidar o usuário a participar ativamente. O engajamento entre mais de um usuário é necessário, ou seja, a participação na experiência é completamente intencional. Ao analisar a anatomia da experiência, proposta por Desmet e Hekkert (2007), verificou-se que a experiência estética é explorada principalmente pelas sensações de frio e calor. O Quadro 2 demonstra a análise deste exemplo.

\begin{tabular}{|c|c|c|}
\hline $\begin{array}{l}\text { CATEGORIAS DA } \\
\text { EXPERIÊNCIA } \\
\text { conforme Buccini } \\
(2006)\end{array}$ & $\begin{array}{l}\text { ESTÁGIOS DA } \\
\text { EXPERIÊNCIA } \\
\text { baseados em Shedroff } \\
(2009)\end{array}$ & $\begin{array}{l}\text { NÍVEIS DA } \\
\text { EXPERIÊNCIA } \\
\text { a partir de Desmet } \\
\text { e Herkkert (2007) }\end{array}$ \\
\hline
\end{tabular}




\begin{tabular}{|c|c|c|}
\hline $\begin{array}{l}\text { Sentidos: calor. } \\
\text { Social: interação } \\
\text { entre pessoas }\end{array}$ & $\begin{array}{l}\text { Atração: a atração é } \\
\text { visual. } \\
\text { Engajamento: o } \\
\text { usuário participa ativa- } \\
\text { mente e precisa engajar } \\
\text { outras pessoas a partici- } \\
\text { par com ele. } \\
\text { Conclusão: reflexão } \\
\text { e sensação de aconchego } \\
\text { com o calor. }\end{array}$ & $\begin{array}{l}\text { Estético: Frio e } \\
\text { calor. } \\
\text { Emoção: Intimida- } \\
\text { de, aconchego, conforto. }\end{array}$ \\
\hline INPUTS & PROCESSAMENTO & OUTPUTS \\
\hline $\begin{array}{l}\text { Fechar o circuito } \\
\text { dando-se as mãos e to- } \\
\text { cando nos locais indica- } \\
\text { dos nas extremidades da } \\
\text { parada de ônibus. }\end{array}$ & $\begin{array}{l}\text { Fechamento de cir- } \\
\text { cuito através da interação } \\
\text { humana. }\end{array}$ & $\begin{array}{l}\text { Calor emitido por } \\
\text { algum atuador de calor, } \\
\text { aquecedor, etc. }\end{array}$ \\
\hline
\end{tabular}

Quadro 2: Análise "Momentos de calor". Fonte: autores.

\section{Análise II - Goodnight Lamp}

A Goodnight Lamp é uma família de luminárias que conecta-se à internet e permite aos usuários comunicar sua presença à amigos e familiares. É composta por quatro peças, que representam casas, sendo uma maior e três pequenas luminárias. Ao acender a lâmpada grande, as três menores irão acender-se instantaneamente, independente do lugar no mundo em que elas se encontram.

De acordo com sua criadora, Alexandra Deschamps-Sonsino, a Goodnight Lamp surgiu a partir do desejo de comunicar-se com amigos e familiares que vivem em outros lugares no mundo.

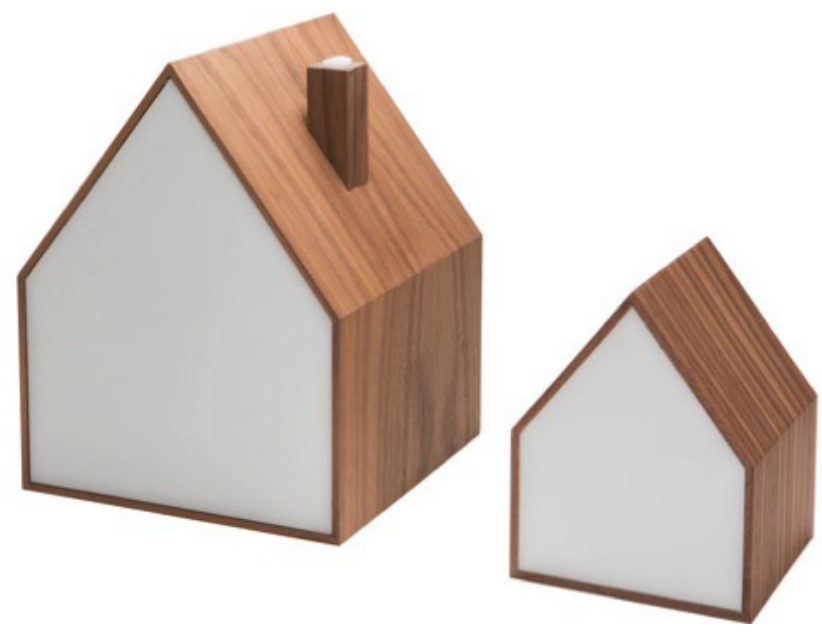

Figura 7: Goodnight Lamp. Fonte: Goodnight Lamp (2014).

A comunicação remota, atualmente, é amplamente difundida. Então, se é possível conversar por vídeo, por exemplo, por que alguém usaria um sinal luminoso para 
comunicar algo? A luminária busca, na sua simplicidade, uma comunicação sutil que baseia-se no sentido de proximidade entre pessoas distantes. Ao acionar a luminária, o usuário expressa sua disponibilidade e seus sentimentos aos receptores, mediado por um objeto. Como dizer "lembrei de você" a um amigo, a experiência de comunicação das luminárias pode envolver sentimentos como saudade, mas sobretudo evoca a representação de presença, visto que para diferentes grupos ela pode ter associações distintas, como saber que o filho foi dormir quando ele apaga a luminária, por exemplo. Contudo, é interessante notar que a comunicação mediada pelo objeto segue um fluxo único: o usuário que possui a luminária maior é o único que pode se manifestar, tornando as outras apenas receptoras.

\begin{tabular}{|c|c|c|}
\hline $\begin{array}{l}\text { CATEGORIAS DA } \\
\text { EXPERIÊNCIA } \\
\text { conforme Buccini } \\
(2006)\end{array}$ & $\begin{array}{c}\text { ESTAGIOS DA } \\
\text { EXPERIÊNCIA } \\
\text { baseados em Shedroff } \\
(2009)\end{array}$ & $\begin{array}{l}\text { NIVEIS DA } \\
\text { EXPERIÊNCIA } \\
\text { a partir de Desmet e } \\
\text { Hekkert (2007) }\end{array}$ \\
\hline $\begin{array}{l}\text { Sentidos: visão. } \\
\text { Social: interação entre } \\
\text { pessoas. } \\
\text { Sentimento: presença, } \\
\text { saudade. }\end{array}$ & $\begin{array}{c}\text { Atração: a atração é } \\
\text { involuntária para os que } \\
\text { possuem as luminárias pe- } \\
\text { quenas. } \\
\text { Engajamento: o usu- } \\
\text { ário que possui a luminária } \\
\text { maior liga. } \\
\text { Conclusão: Usuário } \\
\text { das pequenas luminárias } \\
\text { avalia o sinal. }\end{array}$ & $\begin{array}{c}\text { Estético: Luz. } \\
\text { Significado: Diversas } \\
\text { interpretações. Associação } \\
\text { à disponibilidade e distân- } \\
\text { cia/proximidade. } \\
\text { Emoção: Saudade, } \\
\text { presença. }\end{array}$ \\
\hline INPUTS & PROCESSAMENTO & OUTPUTS \\
\hline $\begin{array}{l}\text { Ligar a luminária } \\
\text { arande. }\end{array}$ & $\begin{array}{l}\text { Todas as partes devem } \\
\text { ser conectadas à internet. }\end{array}$ & $\begin{array}{l}\text { Luminárias pequenas } \\
\text { acendem. }\end{array}$ \\
\hline
\end{tabular}

Quadro 3: Análise "Goonight Lamp". Fonte: autores.

5.3 Análise III - Instalação Hospital Great Ormond Street

O estúdio Jason Bruges desenvolveu uma instalação para o hospital Great Ormond Street, em Londres (Inglaterra), com o intuito de melhorar a jornada das crianças até a sala de anestesia. Para tornar a experiência mais engajadora, a inspiração veio da ideia de enxergar este trajeto como um "caminho da natureza", onde as paredes do hospital funcionam como telas que mostram diversos animais, como cavalos e pássaros, seguindo na direção da sala de anestesia.

O trabalho, que cobre as paredes do corredor, tem essencialmente dois elementos principais; painéis de LED integrados e um papel de parede feito sob medida. O painel de LED é fixado na superfície da parede em diferentes alturas para que seja acessivel às alturas dos olhos e posições dos pacientes que transitam pelo corredor. Por estas superfícies digitais, movimentos de animais são recriados como padrões animados de luz que revelam estes animais atravessando árvores e folhagens da floresta. A peça é formada por diversos painéis, com centenas de lâmpadas de LED. 


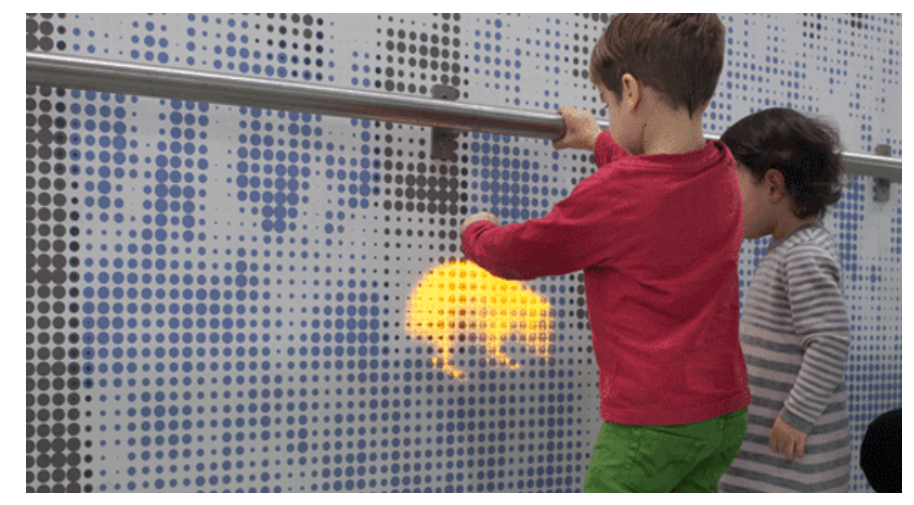

Figura 8: Crianças interagindo com a instalação no hospital. Fonte: Jason Bruges (2013).

Embora não exista uma resposta associada a um input, o projeto busca aprimorar a experiência das crianças em corredores de hospitais através de elementos tecnológicos, criando associações com animais e a natureza que, para as crianças, transformam aquele momento em uma experiência fascinante e mágica.

\begin{tabular}{|c|c|c|}
\hline $\begin{array}{l}\text { CATEGORIAS DA } \\
\text { EXPERIÊNCIA } \\
\text { conforme Buccini } \\
(2006)\end{array}$ & $\begin{array}{l}\text { ESTAGIOSDA } \\
\text { EXPERIÊNCIA } \\
\text { baseados em Shedroff } \\
(2009)\end{array}$ & $\begin{array}{l}\text { NIVEIS DA } \\
\text { EXPERIÊNCIA } \\
\text { a partir de Desmet e } \\
\text { Hekkert (2007) }\end{array}$ \\
\hline $\begin{array}{c}\text { Sentidos: visão. } \\
\text { Motivação: levar a } \\
\text { um determinado lugar no } \\
\text { hospital. }\end{array}$ & $\begin{array}{l}\text { Atração: ao transitar } \\
\text { pelos ambientes que pos- } \\
\text { suem a intervenção, o usu- } \\
\text { ário é atraído visualmente. } \\
\text { Engajamento: os ani- } \\
\text { mais luminosos são dife- } \\
\text { rentes e inesperados. } \\
\text { Conclusão: o caminho } \\
\text { (como se fosse uma trilha) ter- } \\
\text { mina em um lugar específico. }\end{array}$ & $\begin{array}{l}\text { Estético: luzes e cores. } \\
\text { Significação: os ani- } \\
\text { mais e a floresta. } \\
\text { Emocional: diverti- } \\
\text { mento, distração, } \\
\text { encantamento. }\end{array}$ \\
\hline INPUTS & PROCESSAMENTO & OUTPUTS \\
\hline Não se aplica. & $\begin{array}{l}\text { E composto de pai- } \\
\text { neis de LED que ficam por } \\
\text { trás de um papel de pare- } \\
\text { de. Cada animal é gerado } \\
\text { num painel de LED, en- } \\
\text { quanto a floresta é repre- } \\
\text { sentada no papel de parede. }\end{array}$ & Luz (em movimento). \\
\hline
\end{tabular}

Quadro 4: Análise da instalação do Hospital Great Ormond Street. Fonte: autores. 


\section{CONCLUSÃO}

No século XXI, a tecnologia tem possibilitado interações diversas com telas e monitores, seja por toque, botões ou até por movimento. Nesse cenário, o Design com foco na experiência, atrelado a ferramentas da computação física, pode criar meios para interações do usuário ou do ambiente com produtos estáticos, tornando -os expressivos e sensíveis às ações do interator ou aos eventos do ambiente. Concluiu-se com esta pesquisa que, conforme diversos autores já relatam, é imprescindível o entendimento da maneira com que as pessoas interagem com determinados artefatos e como estas interações afetam as experiências que temos.

Além disso, ainda que as experiências proporcionem sensações, significados e emoções que não podem ser projetadas, entende-se que a compreensão dos aspectos propostos pelos diversos autores estudados visa tornar consciente as possibilidades, interpretações e consequências do projeto de Design com foco da experiência do usuário.

Ainda, o caráter sensorial da computação física abre espaço para explorações das camadas estéticas da experiência; a possibilidade de interação, com ação (input) e reação (output), e a sensibilidade agregada a um projeto, permitem explorações de processos cognitivos, exigindo interpretações sobre o produto, seu uso e o ambiente que o rodeia.

A grande variedade de ferramentas e técnicas permite ao designer ampliar seus recursos para conceber projetos inovadores. Com elas, tem-se a habilidade de medir diversos fenômenos e examinar ecossistemas complexos, suas causas e seus efeitos. A prática do designer parte da projetação de elementos necessários ao dia-a-dia, portanto, a computação física pode ser vista como uma ferramenta de grande importância para o desenvolvimento de projetos que visam a melhoria da vida das pessoas, utilizando seu caráter transformador a serviço da sociedade.

Por fim, considerou-se a proposta de análise uma importante ferramenta para identificar a relação entre a computação física e o Design focado na experiência, auxiliando na compreensão da experiência e dos aspectos tecnológicos de projetos desta natureza. Sugere-se que mais análises sejam realizadas em futuras pesquisas, de modo a verificar a aplicabilidade da proposta no estudo de outros projetos que envolvam tecnologia e experiência.

\section{REFERÊNCIAS}

BANZI, Massimo. Getting Started with Arduino. 2ª edição. Sebastopol: O'Reilly, 2011. $130 \mathrm{p}$.

BRAIDA, Frederico. NOJIMA, Vera Lúcia. Design para os sentidos e o insólito mundo da sinestesia. In: VII Painel Reflexões sobre o Insólito na narrativa ficcional. II Encontro Nacional O Insólito como Questão na Narrativa Ficcional. Insólito, Mitos, Lendas, Crenças, 2010, Rio de Janeiro. Anais... Rio de Janeiro: Publicações Dialogarts, 2011. p.216-230. Disponível em: < http://www.ufjf.br/frederico_braida/fi- 
les/2011/02/2010_FREDERICO-BRAIDA-VII_PAINEL_II_ENC_NAC_SIMPOSIO.pdf>. Acesso em 23 mar. 2015.

BUCCINI, Marcos. Design experiencial em ambientes digitais: um estudo do uso de experiências em web sites e junto a designers e usuários de internet. 2006, 144 f. Dissertação (Mestrado em Design) - Universidade Federal de Pernambuco, Recife, 2006. CARDOSO, Cristina et al. Extensão de vida do produto: ciclos de prazer e vínculos afetivos. In: XXX ENCONTRO NACIONAL DE ENGENHARIA DE PRODUÇÃO, São Paulo, Anais... out. 2010. Disponivel em: <http://www.abepro.org.br/biblioteca/enegep2010_tn_sto_117_765_16320.pdf >. Acesso em 23 mar. 2015.

CHIU, Eric. Wearable Tech: Keeping It Close to the Chest. 2014. Disponivel em: <http:// www.wired.com/2014/03/wearable-tech-keeping-close-chest/>. Acesso em: 04 maio 2014.

DESMET, Pieter; HEKKERT, Paul. Framework of Product Experience. International Journal Of Design, Taiwan, 1, 1, abr. 2007. Disponível em: <http://www.ijdesign.org/ ojs/index.php/IJDesign/article/viewFile/66/7>. Acesso em: 31 jan. 2015.

FORLIZZI, Jodi; BATTARBEE, Katja. Understanding Experience in Interactive Systems. Carnegie Mellon University, 2004.

HARTMAN, Kate. Make: Wearable Electronics. [s.l.]: Maker Media, 2014, no prelo.

HASSENZAHL, Marc. User Experience and Experience Design. The Encyclopedia of Human-Computer Interaction. Aarhus, Denmark: The Interaction Design Foundation, 2014. Disponível em <https://www.interaction-design.org/encyclopedia/user_ experience_and_experience_design.html . Acesso em: 5 jan 2015.

IGOE, T. What Is Physical Computing?. 2014. Disponivel em: <http://www.tigoe.net/ blog/what-is-physicalcomputing/>. Acesso em: 11 ago. 2014.

ITP PHYSICAL COMPUTING. [2014?]. Disponível em: <https://itp.nyu.edu/physcomp/>. Acesso em: 14 fev. 2015.

LINDSTROM, Martin. Brandsense. Porto Alegre: Bookman, 2007. 240p.

LÖBACH, Bernd. Design Industrial: Bases para a configuração dos produtos industriais. 1.ed. São Paulo: Edgar Blücher, 2001.

MANZINI, E.; MERONI, A. Il design dei servizi per l'innovazionde della filiera delle produzioni locali di qualità: piattaforme innovative per l'intermediazione alimentare. In: CONGRESSO ITALIANO DI SCIENZA E TECNOLOGIA DEGLI ALIMENTI - CISETA, 8., 2005.

NARDELLI, Nilton César. Design para a experiência e as tecnologias de informação e comunicação. 2007. 223 f. Dissertação (Mestrado) - Curso de Arquitetura, Universidade de São Paulo, São Carlos, 2007.

NORMAN, Donald A. Design Emocional - Por que adoramos (ou detestamos) os objetos do dia-a-dia - Rio de Janeiro: Rocco, 2008.

O'SULLIVAN, Dan; IGOE, Tom. Physical Computing: Sensing and Controlling the Physical World with Computers. Boston: Thomson, 2004. 496 p.

PINE II, Joseph; GILMORE, James. Welcome to the Experience Economy. Harvard Business Review, 1998. Disponível em: <https://hbr.org/1998/07/welcome-to-the-experience-economy> Acesso em 10 jan 2015.

SEYMOUR, Sabine. Fashionable Technology. Viena: Springer-Verlag/Wien, 2008.

SHEDROFF, Nathan. Experience Design 1.1. San Francisco: Experience Design Books, 
2009.

THIEME, Edward. A experiência do usuário como fator no desenvolvimento de produtos. 2012. Disponível em: <http://www.invalley.com.br/blog/?p=162>. Acesso em: 04 maio 2014. 